Daimon. Revista Internacional de Filosofía, $n^{\circ} 75$ (Septiembre-Diciembre) 2018, 117-130

ISSN: 1130-0507 (papel) y 1989-4651 (electrónico)

http://dx.doi.org/10.6018/daimon/328001

\title{
Virtue Perspectivism, Normativity, and the Unity of Knowledge*
}

\author{
Perspectivismo de virtudes, normatividad \\ y unidad del conocimiento
}

MODESTO GÓMEZ-ALONSO**

\begin{abstract}
It will be argued that personal agency, far from lacking epistemic value, contributes to knowledge in a substantial way. To this end, it will be claimed that what Sosa calls an epistemic perspective is necessary to solve the binding problem in epistemology at the three junctures at which it can occur: as the Pyrrhonian question of whether one can rationally endorse one's epistemic rationality; as the problem of the epistemic status of guessing; and as the enquiry into the contribution of the agential perspective for evading coincidental luck. Our aim has been that of elucidating and expanding Sosa's virtue perspectivism.

Keywords: Coincidental Luck, Epistemic Perspective, Ernest Sosa, Guessing, Knowledge, Virtue Perspectivism.
\end{abstract}

\begin{abstract}
Resumen: Se argumentará que, lejos de carecer de valor epistémico, la agencia personal contribuye a la explicación del conocimiento. Para ello, se mostrará que lo que Sosa denomina perspectiva epistémica es imprescindible para la solución del problema de la unidad del conocimiento en las tres formas en las que éste puede plantearse: como el problema pirrónico respecto a la validación de los principios básicos de la racionalidad epistémica; como la pregunta acerca del estatus epistémico de la adivinación; y como la cuestión sobre qué papel podría desempeñar la perspectiva agencial en la superación de la suerte coincidente. Nuestros objetivos son los de elucidar y ampliar el perspectivismo de virtudes de Sosa.

Palabras clave: Adivinación, Conocimiento, Ernest Sosa, Perspectiva epistémica, Perspectivismo de virtudes, Suerte coincidente.
\end{abstract}

\section{Introduction}

While virtue perspectivism has been widely associated with Sosa's bi-level epistemology and it is common knowledge that the notion of epistemic perspective plays a crucial role

Recibido: 15/04/2018. Aceptado: 21/10/2018.

* This article has been funded by the Research Project "Points of View, Dispositions, and Time. Perspectives in a World of Dispositions" (FFI2014-57409-R. Gobierno de España. Ministerio de Economía y Competitividad. Programa Estatal de Investigación, Desarrollo e Innovación.)

** Universidad Pontificia de Salamanca: Profesor Encargado de Cátedra / University of Edinburgh-Eidyn Research Centre: Visiting Researcher. modestomga@hotmail.com / mgomezal@upsa.es Líneas de investigación: Teoría del conocimiento; Metafísica; Filosofía moderna; Epistemología de virtudes; Descartes; Wittgenstein; Escepticismo. Publicaciones recientes: "Wittgenstein, Schopenhauer, and the Metaphysics of Suicide", Aurora. Journal of Philosophy, 30, 49 (2018) 299-321. "Why Only Virtues Can Confer Epistemic Dispositions: The Occasionalist Demon", Disputatio. Philosophical Research Bulletin, 6, 7 (2017) 361-388. 
within Sosa's model, both the specific normative aspect inherent to having an epistemic perspective and the existential tasks to which such perspective is related-the integration of our sensuous and intelligible natures; the overcoming of the cognitively divided self - have usually been ignored by interpreters. As it has been neglected the compatibilist (and, thus, the non-naturalist) view that lies behind Sosa's overall project - one according to which knowledge is an appearance within nature that is at the same time freely produced by the agent, to wit, a rational phenomenon within the sensible world such that it provides us with a warrant for postulating the unity of freedom, rationality and nature.

In Judgment and Agency, Sosa (2015) distinguishes between an instance of judgment, on the one hand, and merely having a belief, on the other. On this view, it is possible for the epistemic agent to experience an attraction to a particular seeming without at the same time willing to affirm that seeming. This view is in keeping with Sosa's emphasis on explaining knowledge in terms of rational agency, as well as with his overall project to offset "an excessive focus on functional belief" (Sosa, Forthcoming, 11) by giving a proper place in epistemology to those dispositions that are "seated in the will." (Sosa, 2015, 210)

Granted that by reflection the agent tears himself away from momentary drives and makes himself independent of sub-personal seemings, it is of the greatest significance that this process does not lead to cognitive disintegration, in which the agent is torn between the claims of reason and the urges of nature. Moreover, it is most important to provide an explanation of how it is possible for the agent to appropriate the deliverances of functional competences for himself and relate to himself in such appropriation. The integration of functional competences and rationality in Sosa's conception of knowledge is carried out in his account of fully apt performance as willed appropriation of the sub-personal performance in accord with the intentional purpose that the agent pursues through his free affirmation. However, under penalty of blocking the understanding of free acts and making them random and arbitrary acts, this account requires a further integration of rationality and willing. The question is how it is possible to have a free judgment that is not eo ipso irrational.

A second challenge for bi-level epistemologies such as Sosa's proposal is to show how voluntary judgments contribute to explaining knowledge. This challenge has been forcefully raised by Hilary Kornblith (2012). Kornblith makes two main criticisms of reflective knowledge. On the one hand, he is most emphatic on the point that reflection (getting an epistemic perspective) does not improve the reliability of first-order competences, thus suggesting that agency has no epistemic value. ${ }^{1}$ On the other hand, he worries about whether reflective knowledge is nothing but animal knowledge on top of animal knowledge, thus jeopardizing the distinction in kinds between animal and human knowledge.

Let me waive Kornblith's point on reflection and first-order reliability and focus on the problem of the epistemic value bestowed by agency. As we shall see shortly, cognitive performances that are set into motion - explicitly or implicitly - by the will possess an epistemic standing far superior to that of functional performances. This is because the impulse towards execution bestowed by the will confers a robust unity to the performance and, in so doing, provides a common cause and a unitary explanation to the act of judging and the aptness

1 On Kornblith's view, the value of agency is parasitical on the value of intellectual autonomy, the latter being an "extra-epistemic value." (Kornblith, 2012, 34) 
of such judgment. The will is both an executive power and the seat of competences. Deprived of such common cause, first-order apt beliefs are merely the intersection of two independent causal chains and are thus coincidental. By removing a variety of luck as important as usually neglected, it is far from true that agency does not contribute to knowledge.

Let me add that, as the will is a spontaneous power that is responsive to reasons, full knowledge is not just more animal knowledge on top of animal knowledge. For one thing, the will is an active power of self-determination that explains the agent's transition from indeterminacy to a determinate state. As such, judgments, unlike seemings, are not determined by causal processes external to the will itself. To be sure, free judgments require an explanation. But, since free acts cannot be explained in a way that makes them unfree, event causation is not the kind of explanation appropriate for this task. Besides, that the will operates in the light of reasons does not mean that reasons are - or can be - the causes (in a Humean sense) of decisions. Unlike causes, which determine happenings, reasons justify and guide deeds. ${ }^{2}$ Since judgments are actions and, as such, are not events that result from passive processes, the way in which they are related to reasons cannot be modelled on the way in which successful performances are related to reliable mechanisms. It is not only that the will is instrumental to the search of reasons but also that rational determination is self-determination. As we shall see, even in those cases in which judgments are performed in the face of no contrary reason, reasons are not limitations of the will.

The considerations of the previous paragraph are not intended to be decisive on the question of whether there is genuine rational agency. Their purpose is merely to show that there is no middle ground between a complete eliminativism with regard to reflective knowledge and the conception of reflective knowledge as knowledge that differs in kind from animal knowledge. It is just not possible to conserve agential reflection while depriving it of the features that make it different from animal knowledge. This is why, in my view, Kornblith's proposal is an unstable halfway house. Eliminativism, on the other hand, comes with a cost. As it was suggested, eliminativism runs the risk of making of fluke successes instances of knowledge.

Here is the plan. In section 2, I will note some analogies and disanalogies between practical and cognitive reason. It is part of my aim here to argue that the epistemic, rational perspective is grounded on a higher-order purpose of the agent such that epistemic agency, far from improving on nature by aiming at the same goals, is constituted by ends different from the teleological purposes of first-order powers. Such unifying purpose introduces a qualitative dimension that makes possible the full and free appropriation of the functional. In section 3, the Kantian question is raised as to how the agent can freely appropriate his basic rational commitments without an arbitrary choice. The problem is that of how rational self-determination -in a

2 Intentions and other mental acts and states that involve the consideration of reasons can clearly be causes —as these are understood in event causation - of doings, as in the case that Davidson considers of the climber who is caused to lose his hold on another man by being unnerved by his intention to rid himself of the extra weight (Davidson, 2001, 79). However, it stands to reason that it is the very fact that in such cases the agent does not freely decide to act according to reasons that explains why the effect is not an action. The agent is rational insofar as he is not compelled by a belief. By acting in the light of reasons, the agent is not caused to act by a psychological state. The intractable problem of deviant causation that plagues causal theories of action is indicative of a category mistake between psychological states (and the causal chains that relate them) and their intentional contents (and how they relate to the free subject and his acts). Although the will is a causal power, it is not a power the operations of which are themselves caused. 
substantive, and not merely in a formal sense - is possible at all. Sosa has faced this issue on several occasions, mostly in his reflections on Pyrrhonism and on whether it is possible for the subject to be freely committed to irrationality. We will follow his lead to clarify how the epistemic perspective can itself be rationally validated. Finally, in section 4 , the robust unity that voluntary judgment confers to epistemic performances will be developed. Agency will thus be shown to be a necessary constituent of knowledge. This article thus aims at addressing the ontological underpinnings of knowledge in a way that makes explicit the agential requirements of knowledge and further elucidates the contents and significance of virtue perspectivism.

\section{Formal Epistemic Agency}

It is intuitive to distinguish an agent's power for determining oneself to act from having one's doings imposed by external causes. However, a voluntary action —one that the agent can rightly claim as his own - is not the result of only a spontaneous power that operates independently of triggers as with the spontaneous decay of uranium. Exercises of the will are uncaused but also responsive to reasons. Reasons operate, however, in view of feasible purposes. Could those purposes be freely and rationally followed so that one's actions would be governed by ends (and norms) that are in turn freely determined by the will? The question is whether full, rational self-determination is even possible and whether the agent, as an agent, is more than the manager of his natural drives. How, if at all, could one integrate the ends of nature within a human cognitive life, a life that ranges well beyond successful and even apt epistemic performances?

In order to shed some light on this problem, it is important to start with the minimal conditions for a free performance. At a minimum, agency requires a power (the will) that is never determined by drives, even in those cases where the subject acts in accordance with the dominant drive. To act freely, the subject has at least to determine himself to follow the urge, making himself independent of it. It is by consciously aiming at an end - by subsuming natural impulses under a unifying purpose - that the agent determines himself, thus freely choosing among the various incentives of which he is aware. This is why Sosa identifies the region of freedom with the domain of endeavours (Sosa, 2015, 192), and why, to be free (and not merely random), a decision has to be grounded on the goals in the endeavour of which the agent acts. Self-determination thus institutes a means-end structure that operates as the standard on the basis of which rational behaviour is made possible. When actively pursuing his ends in the process of making a decision, the agent weighs different courses of action in view of achieving his goal. It is by aligning his action with the dictates of reason that the agent's performances become free and rational, however his awareness may be limited or deceptive. It is then the purpose to which the action is directed - and to which deeds are necessarily anchored - that makes the action neither blind nor arbitrary. As was to be expected, the agent's liberty is made more salient (although it may not be increased) in cases in which the ego experiences conflict between impulses and reasons.

However, the previous considerations are limited to the area of prudential rationality, meaning that the ends to which the performances of practical agents are directed are usually taken from nature, in complete disregard of their origins and rational standing. Thus, the agent imposes a veto on certain drives and impulses in order to pursue more long-standing and valuable natural interests, as when one holds a check on appetites in view of improving 
one's health or prolonging one's life. One could thus say that the monitoring agent produces a totality out of the often chaotic and conflicting multiplicity of impulses in the endeavour of better achieving natural ends and fulfilling natural needs. The subject appropriates the ends of nature by taking control of his nature. In this sense, he is playing the part of nature as well as improving on it. It is thus difficult to see how the agent can be something more than a manager of his impulses. The worry is whether on this view the free, rational subject is not reduced to a vehicle through which nature's ends are better acquired and expressed.

This worry finds several related expressions in the literature of agency. Nozick expresses it by contrasting the contributory and the originative values of actions (Nozick, 1981, 311-312), where the latter value, far from consisting - unlike the former - in the value that an action possesses insofar as it helps realize a natural end, lies in the fact that the action introduces a new end into the world. It is, however, within the Kantian tradition where this point is most emphatic. On the one hand, it is expressed in the search of norms that in the case of conflict, would always trump any other purpose. These guiding principles would produce such firm conviction in the agent that - according to the felicitous words of Fichte - he "accepts the risk of not being able to alter either his manner of acting or the principles in according with which he is acting in this manner." (Fichte, 2005, 160) On the other hand, it is disclosed through the aspiration towards universal rules capable of governing agents independently of who they are, the interests by which they are motivated, and how they are situated or physically constituted. These would be the practical norms - and purposes - of agents insofar as they are agents.

In the domain of practical rationality, the preceding remarks come to mark the transition from prudential behaviour to morality. Let us bear in mind three important points that will be shortly developed. For one, the higher-order norm that governs the actions of full agents is supposed to confer a higher consistency to the will and, in doing so, to make possible a closer unity between the agent and his actions so that the former, by recognizing his deeds as genuinely his own, would be fully committed to them. It is, therefore, as if overcoming prudential rationality would be required for the crystallization of a robust, fully responsible self.

This means, in the second place, that on this view, the emphasis is shifted from acts that manifest one's liberty to abstain from an impulse to decisive actions where what is at stake is the very integrity of the rational self, which is tested. It is as if, from a higher standpoint, practical ends - and the results of practical deliberations - were tinged with a certain indifference and tolerated inasmuch as conflicts with conscience do not arise. Although they are not blind, quotidian acts would thus constitute an intermediate region between the passive and the fully active, where the agent neither takes full responsibility for his doings nor is as wholly committed to them as to accept the risk of making them irrevocably. As it so happens, this perspective presupposes a care for oneself as a moral agent that stands apart from prudential self-caring, to the point of instituting duties that, if unfulfilled, plague the self with regrets wholly independent of whether practical success is achieved. It is doubtless that caring about something is necessary for a meaningful life. However, on the view we are considering, the contents to which the will is directed are not external (and accidental) to the intrinsic dispositions of the will. ${ }^{3}$

3 In contrast with Frankfurt's view, which locates the objects of love in the domain of the empirical self. It is true that according to Frankfurt, such objects become independent of prudential considerations - that they are, as it were, transformed from intentional ends of practical rationality to necessities of the will- through the investment put by the self in them, so that they are tied to a formed self-conception. However, the very fact that 
Two opposing conceptions of the will are, finally, cast in sharp relief. On the one hand, there is the Humean and Schopenhauerian view, according to which the will is a blind force that controls the decisions of intelligent agents. On this picture, the idea of an autonomous, rational power is delusive. On the other hand, the rationalist conceives the will as a power that - at its best - operates independent of empirical desires and motivations, as a rational disposition with its own ends.

I now want to explore certain parallels between practical and epistemic agency. I assume that it is uncontroversial that the minimal requirements for agency are unchanged regardless of whether the goods at which the agent is aiming are prudential goods, such as health, or epistemic goods, such as forming true and reliable beliefs. This just means that agential epistemic performances are necessarily endeavours, which excludes from the domain of freedom acting out of blind, automatic inclinations, regardless of whether they are prejudices inculcated through cultural assimilation or seemings mechanically produced by natural endowments.

The resulting picture of epistemic agency is one in which the subject - far from being determined by seemings - determines himself to follow a seeming by intentionally aiming at an epistemic end. It is the acquisition of such an epistemic end that guides the agent in the process of assigning weights to different, sometimes conflicting, appearances, acting thus as a rule through which the deliverances of first-order cognitive competences are ranked and harmonized. On the plausible view that first-order competences are functionally directed at producing reliable seemings within the range of normal circumstances, it is natural to think that such a goal is also the purpose in the endeavour of which the agent determines himself to affirm. The agent's reflective stance would thus help improve the reliability of first-order competences by subsuming them under a monitoring control.

The first trouble for this minimal conception of epistemic agency comes from classical reliabilism, with its emphasis on the self-regulating character of our cognitive system as it is manifested in the blind production of resultant seemings through a sub-personal processing of a plurality of data. It is just not clear for the reliabilist why the monitoring agent is not redundant, or even obstructive to, the operation of this synthetic mechanism - how, under penalty of overdetermination, agency could be something other than a causally inefficacious epiphenomenon. Most importantly, issues are raised from the opposing camp. After all, on the present approach, the epistemic agent plays the part of functional mechanisms by taking their ends. So, it is again as if the blind teleology of our animal cognitive constitution were using agents as its vehicles.

The latter worry is forcefully displayed by Sosa in his analysis of guessing (Sosa, 2015, 74-77). Sosa takes guesses to be epistemic performances in which the agent affirms $p$ in the

\footnotetext{
they are intrinsically local, to wit, that the unity of purpose that they provide to the agent is intended to guide one's particular life, deprives those commitments of the normative force that we are attempting to capture. This would surely indicate that the conception of the will as a rational power and the view that its objects are such that the subject cannot help himself but act on them do not go together well. It is again as if a strong animal impulse were using the agent as its channel. This is why conceptions that make self-expression either a necessary or a sufficient condition of freedom fall short.

For Frankfurt's views on this issue, see Frankfurt, 2006, 27-52. For a detailed critique of freedom conceived as self-expression, see Yaffe, 2000, 210-216.
} 
endeavour of getting right on $p$. The agent is, therefore, guessing when he determines himself to affirm - and affirmations are a kind of action - with the aim of forming a true, reliable belief by so affirming. Sosa illustrates his point by considering the case of a subject who, in his eye exam, tries to give the right answer even after losing the confidence that he is getting the letters right and who unfailingly and reliably hits the target of truth. ${ }^{4}$ The agent's performances are, by stipulation, reliable. Furthermore, the agent is not acting 'blindly' as a chicken sexer does - at the very least, he acts on purpose and follows the stronger appearance with the aim of getting a true answer. However, there is something missing in his performance, something that makes a mere guess of the affirmation, and so deprives it of a proper epistemic standing. Now, if we ask what is lacking here, our thoughts could be easily deceived by the trappings of the story.

On first consideration, the rub seems to lie in the subject's lack of confidence. However, confidence is a psychological and phenomenological matter. As Sosa puts it, one could artificially gain a boost of confidence without thus increasing one's epistemic standing (Sosa, 2015, 76). In this sense, lack of confidence appears to be indicative of a deeper, fully epistemic phenomenon - the agent's unwillingness to fully commit himself to his affirmation.

On further reflection, it seems appealing to point to the circumstances of the performance to explain the nature of guessing. One could thus say that the very norms that define cognitive games such as game shows and eye exams are such that the epistemic resources the agent can access and the level of rational circumspection that he can rightly exercise are dramatically reduced. On this view, we have to take into account factors such as temporal limitations (urgency) and restricted goals (the objective of eye exams is just to determine one's visual competence) to explain the lower standing of the subject's performances. While action is guided by rational considerations, it is also impaired by the rules of the game.

However, it is important to bear in mind two points regarding these particular contexts. For one thing, they are extenuating circumstances to which the agent can appeal to excuse his cognitive behaviour. By considering those cases, epistemic negligence is made explicit within exceptional contexts in which it is tolerated (or even required). In this sense, the circumstances serve as intimations of a widespread phenomenon. On the other hand, the epistemic deprivation and quantitative reduction of the information pertinent to knowable affirmation that is crucial in those scenarios is not a constitutive feature of guessing. At most, it is the habitual side-effect of the kind of negligence that defines guessing. Though it is true in many cases of guessing that the agent is 'blind' to further relevant information, there is nothing to prevent two agents from being on a par with regard to available information and acting on the same evidence while only one of them is guessing. Hence, it seems to follow that confidence, reliability, and rational affirmation, based on the same range of data that would be sufficient for proper judgment, are - all of them - compatible with guessing. What is then wrong with guessing?

The most obvious point to be made here is that it is the very purpose that guides the agent in such performances - to get it right - that constitutes guessing, regardless of whether the abovementioned factors are also present. Such purpose is a distorting influence that annuls and overrides the care for oneself as a cognitive agent responsive to reasons that is required for

4 Sosa also considers as guesses the right answers of a game show contestant who is not sure whether such answers are right. For this example, see Sosa, 2015, 82. 
knowable judgments. Maybe the evidence on which the guessing agent acts happens to align with the factors that epistemic agents would have to consider to avoid negligence. However, and so long as one's goal trumps that of taking responsibility for one's affirmations, one is -in a qualitative sense - blind to the duties that a proper care for rationality imposes on one's actions. After all, if the evidence had been insufficient for moving the will to one's commitment to one's affirmations, the guessing agent would have affirmed nonetheless.

It is, therefore, as if full epistemic agency would require a higher purpose than that of tracking the truth. The agent also has to affirm in the endeavour of rationally affirming. His overarching goal is thus that of getting the truth by rationally affirming, where rational affirmation is embedded in the objective that the agent pursues. This is why, for Sosa, judgmental performances are directed at getting apt beliefs.

It is clear that this higher purpose introduces a new end into nature and, in doing so, institutes a kind of normativity that goes well beyond the functional, and even the enhanced, reliability provided by monitoring control. Since this rational normativity governs knowable affirmations (judgments), knowledge, like morality, is attributable to only rational animals. Besides, judgments are on par with decisive actions in which the integrity of the rational self is at stake. It is by taking one's claims seriously that one becomes a full agent, one who is bound to his affirmations by a proper care for his rational will and who relates to himself through his commitments. ${ }^{5}$ Guessing falls short because the prerequisites of knowledge are the agent's non-negligent responsiveness to reasons and the corresponding self-determination, which explains why a successful guess does not serve to justify the guesser (the circumstances can, at most, excuse the guesser) and why the agent is not discredited even if his judgment is wrong, so long as he acted to the best of his powers. I think that it is precisely at this point where a disanalogy between practical and epistemic rationality should be noted. Whereas practical considerations in one's interest serve to justify, and not only to excuse, one's behaviour, to the point of being widely tolerated regardless of their moral neutrality, guessing is usually frowned upon by epistemic communities so that the guesser looks, at most, for extenuating reasons - and not for reasons that would vindicate his action as such. Thus, it seems as if the operation of a full rationality, however implicit, would be expected even from quotidian affirmations. This seems to expand our duties, though it does not lessen them. ${ }^{6}$

5 The default expectation of such regard for rationality could plausibly explain why — absent reasons to the contrary - the speaker is entitled to be believed by the addressee so that "it is an insult and maybe an injury not to be believed." (Anscombe, 1979, 150) The point is that the addressee owes respect to the speaker as a free, rational agent, one who is aiming not only to affirm correctly but also to affirm responsibly. One can always be held to account for one's claims, but it is only in virtue of the fact that one is a rational, epistemic agent that one's claims should be believed under penalty of epistemic injustice.

6 Alternatively, the gap between practical and theoretical reason could be bridged by appealing to different contexts of assessment. Thus, practical quotidian acts would be merely excused from the standpoint of morality while perfectly justified from a pragmatic perspective. In the same way, guessing is only excused in view of rational norms, but perfectly justified when other factors are dominant. Nonetheless, it still seems as if our expectations were usually higher in the domain of cognitive affirmation. Plausibly, those reasonable expectations are not only higher but also less influenced by circumstances regarding upbringing, education and personality in the case of beliefs than in the case of actions. 
The objective of making full agency explicit also sheds light on Sosa's view on Pyrrhonism (Sosa, 2015, 229-232). According to his interpretation, the Pyrrhonians aimed at being epistemically governed by goals and policies that were freely determined by the will. To this end, they looked for reasons that by offsetting even the strongest inclinations to assent, would lead to a perfect balance of reasons in support of each alternative. Faced with such a state of rational indeterminacy, the agent is left simply at liberty to make his choice. Here, reasons do not determine the will's outcome one way or the other. Thus, it depends solely upon the agent that something counts as a decisive reason for choice, and so, that the rational deadlock breaks. Inasmuch as the subject assigns the crucial weight to reasons and inclines the balance to a determinate state, he determines himself to act. It is, therefore, as if the Pyrrhonians worked themselves into a state of indetermination of the will in the endeavour of achieving full-fledged self-determination. This is why Sosa says that "the Pyrrhonian philosophy involves an existential stance." (Sosa, 2015, 230) This also explains why the Pyrrhonian decision to be governed by the epistemic policy of following the guidance of nature and the rules of the community in his epistemic performances is, in Sosa's view, perfectly rational. After all, Pyrrhonian choices are guided by reasons, at least in the sense that, with the reasons for and against a course of action cancelling each other, the agent is rationally determined to be a self-chooser - to act freely. The very fact that rational justification comes to an end serves, therefore, to justify one's fundamental commitments.

The trouble lies in two facts. For one, there is a deep difference between those fundamental practical questions for which the subject has to articulate his values through free choices and the overarching decision that the Pyrrhonian tackles, in that the former are inherently situational. This means that what is to be chosen in the first case is a personal form of life so that the choice is not directed to the norms that govern universal, rational behaviour. In contrast, the Pyrrhonian raises for himself the question of whether the agent can freely, rationally determine himself to follow the common conception of epistemic rationality. Thus, he works himself into the very limits of rational, self-reflective scrutiny.

For another, the indirect way in which the Pyrrhonian decision to follow the guidance of nature can be considered rational raises the problem of arbitrariness. For, to say that the Pyrrhonian adopts common epistemic principles in a free and groundless way is to leave open the possibility that his decision is nothing other than arbitrary choice. Inasmuch as unguided choices are not free - they are merely random- it seems as if proper, rational self-determination would require more than the fact that it is rational to choose one way or the other. What is required is that there is only one rational choice to be made. This worry could also be expressed by noting that on this view the Pyrrhonian would be perfectly rational if opting for irrationality. It is the combination of these two issues that raises the question of the ultimate arbitrariness of rational normativity, whether practical or epistemic.

It seems as if we are threatened by an impasse of sorts. On the one hand, minimal agency is clearly insufficient for substantive rational determination, while on the other hand, full agency is being threatened by arbitrariness, as if agency in the fullest and substantive sense

This issue is, however, tangential to the main point that the normativity that rules over knowable affirmations is not animalistic.

7 It is clear that the two requirements cancel each other so that for the choice to be rational, the agent cannot be left simply to make his choice. 
were unattainable. The difference between the two conceptions of agency developed in this section come to be, from a reflective perspective, of little consequence. The important point is that it appears as if we are trapped between animal compulsions and random choices.

\section{Epistemic Agency in its Fullest}

If the agent's commitment to act by the guidance of reason is blind, the problem of rational self-determination that haunted us in the previous section returns with undiminished force. The question is whether one can still relate to oneself by one's commitments in light of the ultimate arbitrariness of those substantial presuppositions that form the backbone of common epistemic rationality.

The trouble lies in the fact that basic epistemic principles are evidential rules on which the whole game of weighing reasons for and against holding empirical beliefs depends. As such, they cannot be supported - or undermined - by any kind of evidence whatsoever: since no experience would have evidential force and direction if those basic principles were false, experience is epistemically neutral regarding those fundamental assumptions that make it epistemically indicative. Thus, it is just wrong to support the belief that we are not BIVs by appealing to empirical beliefs, the justification of which depends in turn on whether we are independently justified in taking ourselves not to be BIVs. One must then be rationally related to the principles of the agential perspective for a rational, integrative relation to empirical claims to even be possible. The Pyrrhonian challenge has to be met on its own terms: Would it be rational to opt out of common epistemic practices? What would be involved in such exercise of self-determination? What is at stake here is the very possibility of a full epistemic perspective, one that yields a positive, affirmative epistemic perspective on the epistemic perspective itself.

It is at the end of Knowing Full Well where Sosa provides us with an a priori warrant for viewing the epistemic perspective as rationally justified (Sosa, 2011, 154-157). Sosa's analysis takes the form of a transcendental argument that, shedding light on the conditions of possibility for ultimate, rational self-determination, concludes that there is only one rational choice to be made - the affirmation of common epistemic rationality. Sosa's argument provides a negative justification of rationality by the rational deflation of Pyrrhonian indeterminacy. Unlike alternative strategies for self-validating rationality, what recommends Sosa's transcendental argument for the present context is its formal, neutral character.

The main point of the argument is that if the principles of epistemic rationality were intrinsically deceptive - something that the Pyrrhonian entertains as a possibility-, then there would be no normative, rational attitude whatsoever to take regarding those principles - neither rational affirmation, nor negation, nor, as the Pyrrhonian recommends, suspension. Which leaves the agent with only one rational attitude to take on the question of whether to hold those principles - that of committing oneself to their truth. The agent is thus rationally determined to endorse rationality.

Put in other words, agents cannot rationally believe that their rational norms are not efficacious and true without also rationally believing that when taking themselves to be rationally operating, they possibly are subject to a cognitive illusion. It is, however, clear that we cannot rationally believe that we might not be rational beings, on pain of making 
of such meta-belief also an illusion. We are, therefore, rationally committed to rationality; the only epistemic perspective that one can take towards one's epistemic perspective is that of rational affirmation; there is no way other than affirmation to be rationally related to the principles of epistemic rationality. As a result, the Pyrrhonian project of unbounding the willing and the rational nature of agents is paradoxical and self-refuting. ${ }^{8}$

From this it follows that because the agent can non-arbitrarily determine himself to follow the intentional purpose of affirming in the endeavour of getting the truth by rationally affirming, the reflective, full appropriation of the agent's acts as his own is attainable. It is true that given its highly demanding and full meditative character, such substantive agency does not contribute to explaining the specific unity that the rational will, per se, confers to ordinary knowledge. However, such agency prevents reason from turning against itself and the consequent discrepancy between higher-order suspension and quotidian, rational affirmation. Such discrepancy would threaten neither the possession of knowledge nor the proper exercise of empirical rationality but - once the agent is made aware of it - would prevent him from responsibly attributing knowledge to himself and rationally claiming that $p$. This is why substantive, reclaimed agency is essential to avert cognitive disintegration - it provides the only kind of explicit relation to rationality that integrates empirical claims within the agent's fullest rational self-conception. The self-assertion of reason prevents the agent from finding himself in the lap of faith - even if it is the faith in rationality.

\section{Coincidental Luck}

Up to now, we have responded directly to the Pyrrhonian problematic. We have also explained why the agent's proper care for his rationality is required for knowable affirmations that are not mere guesses. By themselves, these considerations are sufficient to show that personal agency has epistemic value, regardless of the extra-epistemic value such agency may also have. However, nothing has been said so far as to how agency contributes, if at all, to the mechanics of appropriate successful beliefs with regard to epistemic performances.

The worry is that agency could easily account for the internalist, rational dimension of knowledge while being irrelevant from an externalist standpoint that restricts its attention to the production of beliefs that are linked to the truth by first-order competences. Could those functional mechanisms alone provide a complete causal explanation for the rightly successful epistemic performance, where a 'complete explanation' is one that does not leave open relevant aspects of the occurrence? Could they support the existence of adequately unified apt beliefs? The question is in which way apt beliefs - the explanans - can be causally explained without recurring to the purposes - implicit or explicit - of the epistemic agent.

One hard lesson to learn from the Gettier cases is that beliefs can be competently formed and true while falling short of knowledge. This happens, for example, in cases in which it is a perceptual competence that explains why the agent holds the belief that $p$, it also

8 It goes without saying that the above argument would require further development to be compelling. However, its function within the current context is that of gesturing to the kind of strategy that, once expanded, would have a chance against radical scepticism. Besides, Sosa's argument has the advantage of offering a purely formal criterion on the basis of which the Pyrrhonian argument could be evaded. Notoriously, formal criteria are much more persuasive and easy to formulate than informal ones. 
happens that the belief is true, but the said competence - maybe because it is defective or malfunctioning - does not explain the success of the belief. In those cases, the success is fortuitous - even though the belief has been competently formed. Put another way, these are cases in which two different causal chains co-occur and jointly cause a true belief. The problem is that though the result is causally fully determined, it is also coincidental. An occurrence is coincidental, not because it is uncaused, but because it lacks a common cause for the causal sequences that bring about the result. Here, what explains the existence of the belief - visual competence - is unrelated to what explains its accuracy.

It was with the objective of providing a common cause for belief formation and belief success that Sosa substituted apt beliefs for competent, true beliefs as cognitively relevant. ${ }^{9}$ Apt beliefs are such that not only the existence of the belief but also its success are due to the relevant competence. Thus, the question of why the agent holds the belief that $p$ and the question of why this belief is successful are answered by pointing to the same factor. Apt beliefs are competently produced by a reliable virtue. But, is this enough?

The worry can be expressed as follows. Granted that S's belief that $p$ is apt, it is still true that $\mathrm{S}$ would have believed that $p$ even if the competence were defective or malfunctioning. The truth of this counterfactual indicates that first-order aptness is not logically embedded in the conditions for competently holding beliefs so that it is false that $\mathrm{S}$ would hold that belief only if such belief were likely apt. It is, therefore, as if the same competence would explain the belief's existence, on the one hand, and its aptness, on the other, in two different senses - as the causal basis on which the belief is formed and as a reliable virtue.

Let me dwell a little bit on this point. It is the fact that the competence is reliable that makes true that $S$ would not too easily have so believed while his belief is inapt. This means that insofar as the belief is based on a reliable competence, if the belief is competently formed, it is also likely apt. Reliability automatically excludes the likely existence of inapt beliefs formed on such a basis. The problem lies in the fact that while the competence's reliability explains why beliefs formed on the basis of the competence are likely apt, it does not explain why $S$ came to believe so - after all, $\mathrm{S}$ does not determine himself to so believe because the belief would be likely apt; the belief could have been held, just as it is, in the absence of aptness. This is why the bare competence as the cause of believing and its reliability as the ground of aptness fall apart. Unlike what occurs in the Gettier cases, the belief's success is not fortuitous. However, that the subject holds an apt belief is.

Aptness improves on mere success because when beliefs are apt, it is not by luck - on the contrary, it is by competence- that they are successful. However, even so, it is only by luck that $\mathrm{S}$ came to believe in a way that happens to be apt. There is no underwriting first-order reliability that would explain his believing in such a way that not only the success of the belief but its very existence would be apt. Provided that the agent does not hold the belief because of its likely aptness, it is just coincidental that he holds an apt belief - a belief which, of course, is not coincidentally successful. The agent does not aptly attain his apt belief, and so, the result, though causally determined, is contingently and externally brought about. The two causal lines combine, but they are not made for each other. What is then required is a common

9 Sosa is most emphatic on this point in the Chapter 3, "Virtue, Luck and Credit", of A Virtue Epistemology. See Sosa, 2007, 94-97. 
factor that precisely avoids the involvement of coincidence in belief formation/belief aptness relations. Such factor must be a second-order competence - one the reliability of which would underwrite the belief's existence. It must also provide the internal relation between affirmation and aptness that a robust, non-coincidental unity of epistemic performances requires. This suggests, in turn, that we have to leave behind those beliefs understood as animal credences and implicit confidence and come to consider, in line with Sosa's Cartesian view (Sosa, 2017, 6-7), judgmental affirmations - those affirmations underwritten by agency.

The point is that voluntary causes of apt performances are directed upon the occurrence of such events in such a way that it is the end at which the agent aims that explains the existence of the affirmation. The responsible agent intentionally determines himself to affirm in the endeavour of getting the truth by rationally affirming so that he would not have affirmed if his affirmation had not been likely apt. Since the agent would judge only if such judgment were likely apt, it is not by coincidental luck that he holds an apt judgment. The judgment is formed in the view of likely aptness. As such, the act of judging is underwritten by the same evaluative competence that is manifested in fully apt performances.

There is just no way to pry apart rational competence as the ground for rightly successful judgments and as the causal basis of judgmental acts. As a matter of fact, here, one cannot coherently speak about causal bases at all because the act of judging has its source not in causes but in the very same reasons that explain why the judgment is apt. It is, therefore, the same aspect of the competence that the subject exercises if properly caring for the situation of his performance, his shape when performing and the standing of his cognitive abilities that explains why the agent aptly attains his apt beliefs and why he came to judge as he did. The agent rationally appropriates his affirmation and the first-order competence that produces apt performances - both of them become voluntary. Full aptness and judgment are made for each other.

It is clearly possible that even a rational, responsible judgment could fall short of success. It is also possible that it could be successful just by luck. However, those possibilities do not loosen in the slightest the bond between judgment and full knowledge. It is still true that were the success due to the second-order competence, the explanation of why the success is not fortuitous would converge with the explanation as to why the agent formed that judgment. In those cases of epistemic accomplishment, the act of judging and the cognitive achievement of the agent would manifest the same rational competence.

Provided that we can say, as we plausibly can, that coincidental luck can be avoided only if the subject affirms in the light of reasons and with the purpose of achieving rational, apt affirmation, it is clear that purely functional explanations of knowledge are inadequate. On the one hand, they are incomplete. After all, even if we had satisfied ourselves that we know all the mechanisms that resulted in S's holding an apt belief, such explanation would still leave open the question of whether the resultant fact is coincidental or not. Given that such a fact would be left underdetermined by first-order explanations and that there is an intuitive factual distinction between S's non-coincidental affirmation and the coincidental belief of his modal counterpart that the functional reconstruction alone cannot capture, the limitations of such procedure are obvious. On the other hand, functional explanations cannot explain knowledge because genuine knowledge requires the agent's act of affirming not be merely contingently connected to success but to be connected in such a way that in the right circumstances, 
affirming results in success. In normal circumstances, affirming must be internally related to successful performances so that it is fulfilled by a cognitive achievement that far from being an autonomous event, is the necessary development of the act of affirming itself. Deprived of such robust unity - one that only agency can provide - the agent is not creditable for his success in any meaningful sense, since such success is something that necessarily takes place outside his awareness and over which he has no control whatsoever. The agent's competence in affirming is just the competence that the accuracy of his judgments fully displays.

The unity of knowledge is thus grounded upon the rational will, which is necessary to solve the binding problem in epistemology at the three junctures at which it can occur: as the Pyrrhonian question of whether one can rationally endorse one's epistemic rationality; as the problem of whether agency is nothing more than a monitoring control in the service of firstorder competences; and as the enquiry into the contribution of agency in the acquisition of quotidian knowledge. The rule of the rational will that operates within an epistemic perspective makes the agent's cognitive integration possible by preventing arbitrariness, guessing and coincidental luck. It is thus much more than the epiphenomenal froth of standard reliabilism. As a matter of fact, the competences of the will look more like the headstone of the corner.

\section{References}

Anscombe, E. (1979), «What is it to Believe Someone?», in: C.F. Delaney (ed.): Rationality and Religious Belief, South Bend: University of Notre Dame Press, pp. 141-151.

Davidson, D. (2001), Essays on Actions and Events, Oxford: Oxford University Press.

Fichte, J.G. (2005), The System of Ethics, Cambridge: Cambridge University Press.

Frankfurt, H.G. (2006), Taking Ourselves Seriously and Getting It Right, Stanford, California: Stanford University Press.

Kornblith, H. (2012), On Reflection, Oxford: Oxford University Press.

Nozick, R. (1981), Philosophical Explanations, Cambridge, Massachusetts: Harvard University Press.

Sosa, E. (2007), A Virtue Epistemology. Apt Belief and Reflective Knowledge, Volume I, Oxford: Clarendon Press.

Sosa, E. (2011), Knowing Full Well, Princeton and Oxford: Princeton University Press.

Sosa, E. (2015), Judgment and Agency, Oxford: Oxford University Press.

Sosa, E. (2017), Epistemology, Princeton and Oxford: Princeton University Press.

Sosa, E. (Forthcoming), «Replies to Comments on Judgment and Agency», Philosophical Studies, Forthcoming, pp. 1-13.

Yaffe, G. (2000), «Free Will and Agency at Its Best», Philosophical Perspectives, 14, pp. 203-229. 